\title{
Calcitonin gene-related peptide relates to cough sensitivity in children with chronic cough
}

\author{
A.B. Chang**\#, P.G. Gibson ${ }^{\star}$, J. Ardill ${ }^{+}$and L.P.A. McGarvey ${ }^{\S}$
}

ABSTRACT: Airway neuropeptides, in particular calcitonin gene-related peptide (CGRP), are likely to be important in the pathogenesis of chronic cough. The present authors evaluated the following: 1) the relationship between cough sensitivity and bronchoalveolar lavage (BAL) neuropeptides; and 2) the effect of reflux oesophagitis (RO) on cough, cough sensitivity and BAL neuropeptides in children not selected for cough. It was hypothesised that CGRP would be increased in children with chronic cough and would relate to cough sensitivity.

Capsaicin cough sensitivity was performed in children undergoing gastro-duodenal endoscopy. CGRP, substance P and neurokinin A were measured in BAL obtained nonbronchoscopically. Children were defined as "coughers" if chronic cough was present.

Coughers $(n=21)$ had significantly reduced cough sensitivity but were just as likely as noncoughers $(n=19)$ to have RO. The median CGRP was significantly higher in coughers with oesophagitis than in noncoughers with oesophagitis. CGRP significantly negatively correlated to cough sensitivity in coughers but not in noncoughers.

Elevated calcitonin gene-related peptide, but not substance $P$ or neurokinin $A$, is only associated with chronic cough in children when oesophagitis coexists. Calcitonin gene-related peptide in bronchoalveolar lavage relates to cough sensitivity and is likely to be important in the pathophysiology of chronic cough.

KEYWORDS: Calcitonin gene-related peptide, capsaicin cough sensitivity, children, cough, sensory neuropeptides

hronic cough is a commonly encountered symptom and can result from a wide variety of pulmonary and nonpulmonary conditions. Irrespective of its aetiology, chronic cough causes significant morbidity $[1,2]$ and is associated with enhanced cough sensitivity in children [3,4] and adults [5-7]. Cough sensitivity is commonly measured using capsaicin cough challenge $[7,8]$.

Understanding the mechanisms of disease processes is an important step in the advance of medicine. In the area of cough, the majority of such data have been obtained from animal studies whereby significant interspecies differences exist [9]. The mechanisms associated with chronic cough in humans include neurogenic inflammation through the sensory pathway [1012] and vanilloid receptor (VR) activation [13]. VRs (such as transient receptor potential vanilloid-1 (TRPV-1) receptors) have been found to be likely contributors to an enhanced cough response in chronic persistent cough [13, 14]. In
29 adults with chronic persistent cough from diverse causes, GRONEBERG et al. [13] described a significant correlation between capsaicin tussive response and the number of TRPV-1-positive nerves of airway mucosal biopsy specimens. In animals, the cellular distribution of TRPV-1 neurons is such that they occur in sensory neurons [15]. Sensory nerve stimulation primarily involves neurogenic inflammation whereby neuropeptides, such as calcitonin gene-related peptide (CGRP) and substance $\mathrm{P}(\mathrm{SP})$, play a key role $[9,12]$.

In the airways, neuropeptides thought to be particularly important include SP, neurokinin (NK)A and CGRP $[9,16]$. SP, NKA and CGRP are pro-inflammatory sensory neuropeptides [9], although the pulmonary effects of CGRP are also anti-inflammatory [16]. In particular, CGRP has been shown to be important in the mechanism of chronic cough [16, 17]. In human studies, increased CGRP but not SP immunoreactive nerves were found in biopsies of adults with

\section{AFFILIATIONS}

*Dept of Respiratory Medicine, Royal Children's Hospital, Brisbane, Queensland,

\#Menzies School of Health, Darwin, Northern Territory, and

•Hunter Medical Research Institute, John Hunter Hospital and University of Newcastle, Newcastle, New South Wales, Australia.

+Wellcome Research Labs, Royal

Victoria Hospital, and

§TTe Queen's University of Belfast, Belfast, UK.

CORRESPONDENCE

A.B. Chang

Dept of Respiratory Medicine

Royal Children's Hospital

Herston

Queensland 4029

Australia

Fax: 61736361958

E-mail: annechang@ausdoctors.net

Received:

November 182006

Accepted after revision:

January 092007

SUPPORT STATEMENT

The present study was funded by the Royal Children's Hospital

Foundation. A.B. Chang and P.G.

Gibson are supported by the

Australian National Health and

Medical Research Council, Canberra,

Australia.

STATEMENT OF INTEREST

None declared.

European Respiratory Journal

Print ISSN 0903-1936

Online ISSN 1399-3003 
chronic cough [18]. These adults also had significantly increased cough sensitivity to capsaicin (i.e. a reduced threshold to elicit a cough response) [18]. In animal models, gastrooesophageal reflux (GOR) is associated with sensory nerve stimulation [19].

Whether data in airway mucosal biopsies can be related to bronchoalveolar lavage (BAL) in the pathophysiology of chronic cough is unknown. To date, no studies that have related cough sensitivity to these key neuropeptides (CGRP, $\mathrm{SP}, \mathrm{NKA}$ ) in BAL. Indeed, there is currently no data on BAL quantification of these neuropeptides in children either with or without chronic cough. BAL provides different and complementary information to mucosal biopsy, with the advantage that a broader range of airways are sampled, both in terms of the numbers and size of the airways sampled.

There are several unique and important features of the population used in the present study. Prior studies have used selected populations of adults presenting with cough [13, 18], and this may select individuals with an abnormal airway response. In order to avoid this potential bias in the present study, children have been studied presenting for upper gastrointestinal endoscopy where there was no selection bias for coughing [20, 21]. In addition, the present authors have evaluated neuropeptides in children where data are scant. Gastro-oesophageal reflux disease (GORD; symptoms or complications of GOR [22]) is associated with chronic cough but the mechanism and "cause and effect" remains controversial in humans [23]. The present authors conducted a study to evaluate the following: 1) the relationship between cough sensitivity and BAL neuropeptides; and 2) the effect of reflux oesophagitis on cough, capsaicin cough sensitivity and BAL neuropeptides in children unselected for the presence of chronic cough. It was hypothesised that CGRP would be increased in children with chronic cough and would relate to capsaicin cough sensitivity.

\section{METHODS}

Children $<14$ yrs of age undergoing elective flexible upper gastro-intestinal endoscopy were invited to participate in the study, as previously described [20, 21]. Briefly, children were enrolled for the study on the morning of their procedure (flexible upper endoscopy performed under general anaesthesia including endotracheal intubation). Medical history was obtained from a parent on a standardised proforma for all children. Parent(s) also scored their child's cough on a validated cough visual analogue scale of 1 (no cough) to 10 (most severe cough) [24]. Exclusion criteria of children were as follows. 1) Neuro-developmental abnormalities; 2) known underlying cardiorespiratory disease other than asthma; and 3) a clinical history of primary aspiration (coughs and chokes with feeds at least twice a week). Children were defined as "coughers" (C+) if the parents or consultant (gastroenterologist or respiratory paediatrician) had elicited a history of cough in association with GORD [20]. Reflux oesophagitis (RO) was considered present if histology of an oesophageal biopsy showed RO, as determined by pathologists blinded to the child's respiratory history. Written consent was obtained and the study approved by the human ethics committee of the Royal Children's Hospital (Brisbane, Queensland, Australia).
Capsaicin cough sensitivity test and spirometry were performed on children aged $\geqslant 6$ yrs prior to endoscopy. The cough sensitivity test described specifically for children was performed using a single inhalation dosimeter technique [8]. Outcomes of cough sensitivity test were defined as the concentration of capsaicin that stimulated $\geqslant 2$ coughs (C2) and defined that which stimulated $\geqslant 5$ coughs (C5). Increased cough sensitivity is represented by a lower C2 and/or lower C5 values, i.e. a lower concentration of capsaicin required to elicit coughs. Spirometry was performed using a turbine spirometer (Kit; Cosmed, Rome, Italy) and Australian values were used for predictive values [25].

\section{$B A L$ and $B A L$ examination}

BAL was obtained using a standardised and repeatable [26] nonbronchoscopic technique. Briefly, with the child's head turned to the left, a catheter was passed as far as possible through the endotracheal tube, ensuring that it went beyond the estimated carina site. Two aliquots of sterile normal saline $\left(1 \mathrm{~mL} \cdot \mathrm{kg}^{-1}\right.$ to a maximum of $\left.20 \mathrm{~mL}\right)$ were instilled and suctioned into separate mucus traps. The second aliquot was used for BAL cellularity and neuropeptide analysis. The first aliquot was used for microbiology, the results of which have been previously described [20]. A cell count was performed (by blinded cytologists) on the cell suspension, cytocentrifuge slides were prepared and stained (modified Wright's stain, Diff Quik; Lab Aids, Narrabeen, NSW, Australia) for cell differential profile. Protease inhibitor (see Appendix) was added to the BAL supernatant, and the mixture was immediately frozen and kept at $-80^{\circ} \mathrm{C}$ until it needed to be thawed for analysis.

\section{Analysis of CGRP, NKA and SP}

The BAL specimens were prepared for assay of neuropeptides using an established technique using Sep-Paks ${ }_{\circledR}$ (C18 Sep-Pak; Waters, Milford, MA, USA). Specimens were applied to a C18 Sep-Pak, washed and eluted with an acetonitrile-trifluoroacetic acid $1 \%$ solution (60:40 volume/volume). The eluate was dried using a rotary evaporator and the residue reconstituted in buffer prior to assay. The specimen was reconstituted to concentrate the sample by two-fold. The recovery of peptides via this extraction procedure is $>90 \%$.

NKA was measured using an in-house (The Queen's University of Belfast, Belfast, UK) radioimmunoassay. The antibody was raised in guinea pig to synthetic human NKA (Bachem, St Helens, UK). The antibody was directed to the amino terminal; it cross-reacted fully with NKB and neuropeptide $\mathrm{K}$, and cross-reaction with SP was $<0.1 \%$. Radiolabelled NKA was purchased from GE Healthcare (St Giles, UK). The limit of the assay was $2 \mathrm{ng} \cdot \mathrm{L}^{-1}$. There was no external quality control system available for NKA; however, three internal controls were added to each assay batch. The coefficient of inter- and intra-assay variation was 9.8 and $6.2 \%$, respectively. CGRP was measured by radioimmunoassay using a commercial antiserum to human CGRP (antibody code RAS-6012N; Peninsula Laboratories, San Carlos, CA, USA). The antibody cross-reacted with human CGRP-I and -II. Radiolabel was purchased from GE Healthcare. Three internal quality control specimens were included in each assay batch. The limit of detection was $2 \mathrm{ng} \cdot \mathrm{L}^{-1}$ and inter- and intra-assay variation was 
11.5 and $7.5 \%$, respectively. SP was measured by ELISA using a commercial kit (catalogue number DE1400; R\&D Systems, Minneapolis, MN, USA). The assay did not cross-react with NKA, NKB or neuropeptide K. The limit of detection of the assay was $8 \mathrm{ng} \cdot \mathrm{L}^{-1}$.

\section{Statistical analysis}

Children were categorised into coughers $(\mathrm{C}+)$ and noncoughers (C-) with $\mathrm{RO}(\mathrm{RO}+)$ and without $\mathrm{RO}$ (RO-). The Chisquared test was used to compare categorical variables between groups, with a continuity correction used when the table cell was $<5$. Data were not normally distributed and, thus, nonparametric analyses were used: the Mann-Whitney U-test for comparisons between two groups and the KruskalWallis test when $>2$ groups were compared. Medians and interquartile ranges (IQRs) were used for all descriptive data. Kendall's tau-b was used to examine correlation among variables as the sample size was small. A two-tailed p-value $<0.05$ was considered significant.

\section{RESULTS}

The median age of the 40 children (26 males) recruited was 9.6 yrs (IQR 6.4; IQRs are given throughout as the 75th quartile minus the 25th quartile). Most $(n=36,90 \%)$ children were clinically suspected of having GORD, and oesophagitis was present in $23(57.5 \%)$ children. Coughers $(n=21)$ were just as likely as noncoughers $(n=19)$ to have GORD $(p=0.538)$. Spirometry was normal in all children who could perform spirometry $(n=27)$, with a median forced expiratory volume in one second of $99.8 \%$ predicted, and a forced vital capacity of $100.3 \%$ pred. In the C+ group, cough was present for a median (IQR) time of 160 (186) weeks. The median cough score was significantly higher in the C+ group (5 (3.5)) than in C- (median score of 1 , i.e. no cough; $\mathrm{p}<0.0001)$. No difference was observed in the cough score or length of cough between $\mathrm{RO}+$ and $\mathrm{RO}$ - groups ( $\mathrm{p}=0.57$ and 0.96 , respectively).

There was no significant difference in BAL cellular profile (percentages of neutrophils, macrophages, lymphocytes, eosinophils or total cell count) between the $\mathrm{C}+$ and $\mathrm{C}$ - groups (table 1). However, the RO- group had a significant but small increase in BAL neutrophil percentage when compared with the $\mathrm{RO}+$ group $(\mathrm{p}=0.01)$. No difference was observed in BAL percentages of macrophages, lymphocytes and eosinophils in children with and without RO. There was no difference in CGRP, SP or NKA levels between either the C+ and C-groups or the $\mathrm{RO}+$ and $\mathrm{RO}$ - groups. Coughers had a lower $\mathrm{C} 2$ but not C5. Capsaicin cough sensitivity was similar between $\mathrm{RO}+$ and RO- groups (table 1).

When grouped by the presence of cough and $\mathrm{RO}, \mathrm{C} 2$ was significantly different among the groups $(p=0.013)$, but there was no significant difference in BAL cellularity, SP or NKA (table 2). $\mathrm{C} 2$ was lowest in the $\mathrm{C}+\mathrm{RO}+$ group and highest in the C- RO- group. C5 and CGRP values were just outside the significant value $(p=0.06$ and 0.07 , respectively). In two group comparisons, CGRP was significantly different between $\mathrm{C}+\mathrm{RO}+$ and $\mathrm{C}-\mathrm{RO}+$ groups ( $\mathrm{p}=0.02$; fig. 1 ), but not between the other groups (p-values of 0.07-0.74). Similarly, C5 was significantly lower in $\mathrm{C}+\mathrm{RO}+$ compared with $\mathrm{C}-\mathrm{RO}+$ $(p=0.04)$, but not in the other two group comparisons ( $p$ values of $0.09-0.63)$.

$\mathrm{C} 2$ and C5 were significantly ( $\mathrm{p}=0.031$ and 0.020 , respectively) and negatively correlated $(\mathrm{r}=-0.51$ and -0.55 , respectively) to

\begin{tabular}{|c|c|c|c|c|c|c|}
\hline & $\mathrm{C}+$ & C- & p-value ${ }^{\#}$ & RO+ & RO- & p-value \\
\hline Subjects $n$ & 21 & 19 & & 23 & 17 & \\
\hline \multicolumn{7}{|l|}{ Demographics } \\
\hline Age yrs & $9.1(4.5)$ & $9.8(7.8)$ & 0.46 & $9.7(4.3)$ & $8.9(8.0)$ & 0.33 \\
\hline Lymphocyte \% & $3.0(3.5)$ & $2.5(13.8)$ & 0.77 & $3.5(7.5)$ & $2.5(2.3)$ & 0.60 \\
\hline Neutrophil \% & $6.5(4.3)$ & $4.0(8.3)$ & 0.41 & $4.5(3.8)$ & $7.0(6.3)$ & $0.01^{+}$ \\
\hline Macrophage \% & $90(8.1)$ & $80(67.0)$ & 0.67 & $86(33.0)$ & $88(9.7)$ & 0.41 \\
\hline Eosinophil \% & $0(0)$ & $0(0)$ & 0.33 & $0(0)$ & $0.0(0.8)$ & 0.77 \\
\hline Total cell count $\times 10^{-6} \cdot \mathrm{L}^{-1}$ & $86(60)$ & $46(169.0)$ & 0.21 & $59(108)$ & $83(62.5)$ & 0.25 \\
\hline \multicolumn{7}{|l|}{ Capsaicin sensitivity } \\
\hline $\mathrm{C} 2 \mu \mathrm{M}$ & $14.7(19.5)$ & $39(58.5)$ & $0.018^{+}$ & $19.5(9.7)$ & $14.7(39.0)$ & 0.17 \\
\hline $\mathrm{C} 5 \mu \mathrm{M}$ & $29.3(68.2)$ & $58.5(58.5)$ & 0.13 & $39(29.2)$ & $29.3(117.0)$ & 0.06 \\
\hline
\end{tabular}

Data are presented as $\mathrm{n}$ or median (interquartile range given as the 75 th quartile minus the 25th quartile), unless otherwise indicated. CGRP: calcitonin gene-related peptide; C2: the concentration of capsaicin that stimulated $\geqslant 2$ coughs; C5: the concentration of capsaicin that stimulated $\geqslant 5$ coughs. ${ }^{\#}$ : comparisons between C+ and C- groups using the Mann-Whitney U-test; ${ }^{\prime}$ : comparisons between RO+ and RO- groups using the Mann-Whitney U-test; ${ }^{+}$: $\mathrm{p}$-value is significant. 


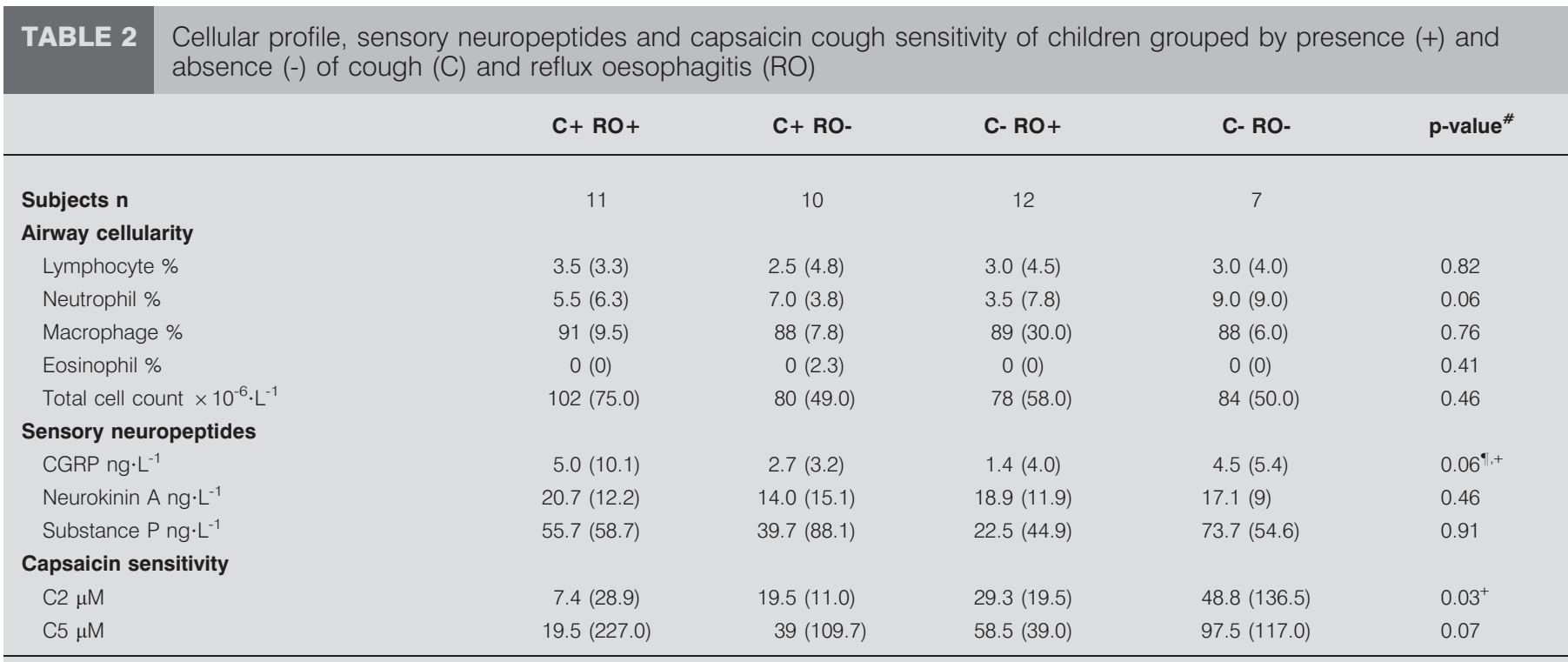

Data are presented as $\mathrm{n}$ or median (interquartile range given as the 75 th quartile minus the 25th quartile), unless otherwise indicated. CGRP: calcitonin gene-related peptide; $\mathrm{C} 2$ : the concentration of capsaicin that stimulated $\geqslant 2$ coughs; $\mathrm{C} 5$ : the concentration of capsaicin that stimulated $\geqslant 5$ coughs. ${ }^{\#}:$ Kruskal-Wallis test; " $:$ C+ RO+ was significantly different to $\mathrm{C}$ - $\mathrm{RO}+(\mathrm{p}=0.02){ }^{+}$: $\mathrm{p}$-value is significant.

CGRP in coughers (fig. $2 \mathrm{a}$ and $\mathrm{b}$ ) but not in noncoughers $(r=0.28, p=0.28$ for $\mathrm{C} 2 ; \mathrm{r}=0.29, \mathrm{p}=0.324$ for $\mathrm{C} 5$; fig. $2 \mathrm{c}$ and $\mathrm{d})$. Cough sensitivity did not relate to any other parameter in coughers and noncoughers. Cough sensitivity also did not correlate to CGRP, NKA, SP or to any BAL cellularity in the total group ( $\mathrm{p}$-values of $0.06-1.0)$.

\section{DISCUSSION}

The current authors have previously shown that in most children chronic cough was not associated with $\mathrm{RO}$ alone [20] and that airway neutrophilia is absent in children with RO [21]. The present study adds to this information by showing that in the BAL of 40 children, CGRP, NKA and SP levels in children

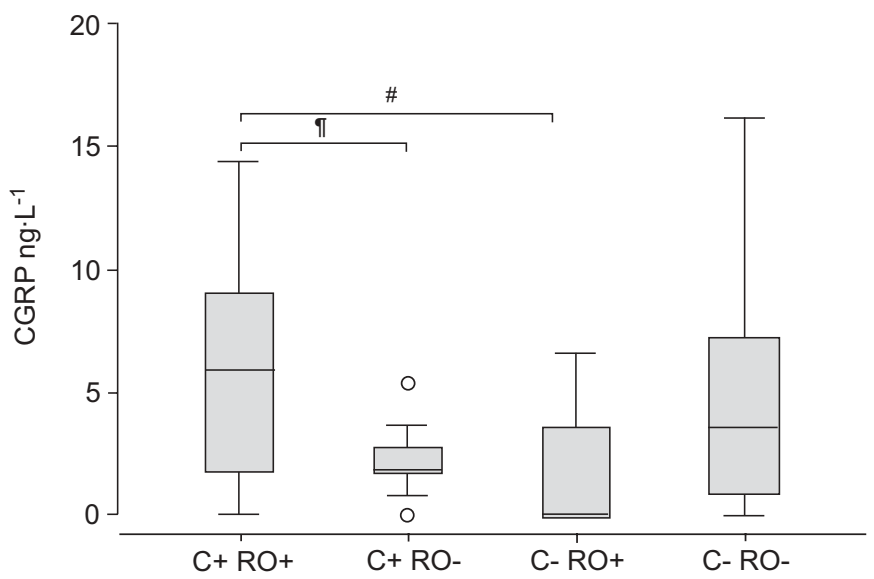

FIGURE 1. Median and interquartile range of calcitonin gene-related peptide (CGRP) in bronchoalveolar lavage of children grouped by presence $(+)$ and absence (-) of cough (C), and reflux oesophagitis (RO). The CGRP level was significantly different between $\mathrm{C}+\mathrm{RO}+$ and $\mathrm{C}-\mathrm{RO}+$ groups ( $: \mathrm{p}=0.02$ ), but not between the other groups ( $p$-values of $0.07-0.74$ ). ${ }^{\top}: p=0.07$. $O$ : outliers. with chronic cough were not significantly different from those without cough. However, children with cough and biopsyproven RO had significantly higher CGRP than children with reflux but without cough. Furthermore, CGRP, but not NKA or SP, related significantly to capsaicin cough sensitivity in children with chronic cough but not in those without cough.

The present study is the first to examine these neuropeptides in the airways of children with and without chronic cough. Neurogenic inflammatory mediators, particularly CGRP, have been implicated in the pathogenesis of chronic cough $[12,18]$. The present finding of CGRP in the BAL also being related to cough sensitivity in coughers but not in noncoughers is perhaps not surprising. In biopsy specimens, CGRP immunoreactivity has been found to be related to cough sensitivity in adults with chronic cough [18]. This is likely to relate to the plasticity of the peripheral nervous system, with neurotrophins altering the pattern of innervation changes in inflammatory disease, as SP- and CGRP-immunoreactive nerves are sparse in normal human airways [27]. CGRP-containing airway innervating nerves originate from the nodose-jugular ganglia (among other ganglia) [16], which is also the ganglia found to be central in the neurophysiology of the cough reflex [28]. It is thus biologically possible that upregulation of these nerves causes a spill-over in the airways. CGRP can be released by noxious stimuli and plasma extravasation may occur [16], and thus CGRP in BAL may either occur from or lead to plasma extravasation. Increased pulmonary blood flow has been found to be associated with elevated levels of plasma CGRP [29], and high BAL levels may reflect circulating levels when airway disease is present, such as in circumstances when cough is reflective of airway disease. In an animal model, DAOUI et al. [19] demonstrated that protein extravasation in the airways can be induced by hydrochloric acid infusion into the oesophagus, and that extravasation into the airways is mainly dependent on the release of tachykinins. 

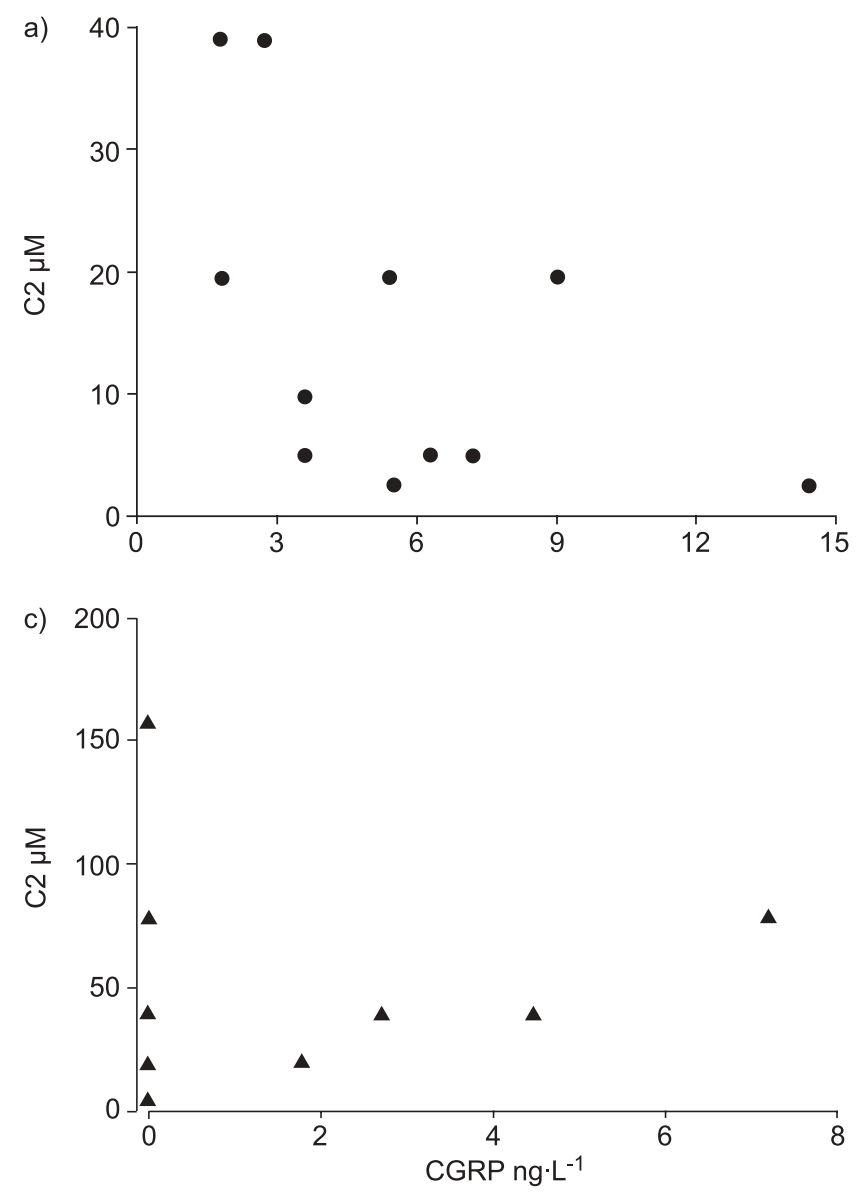
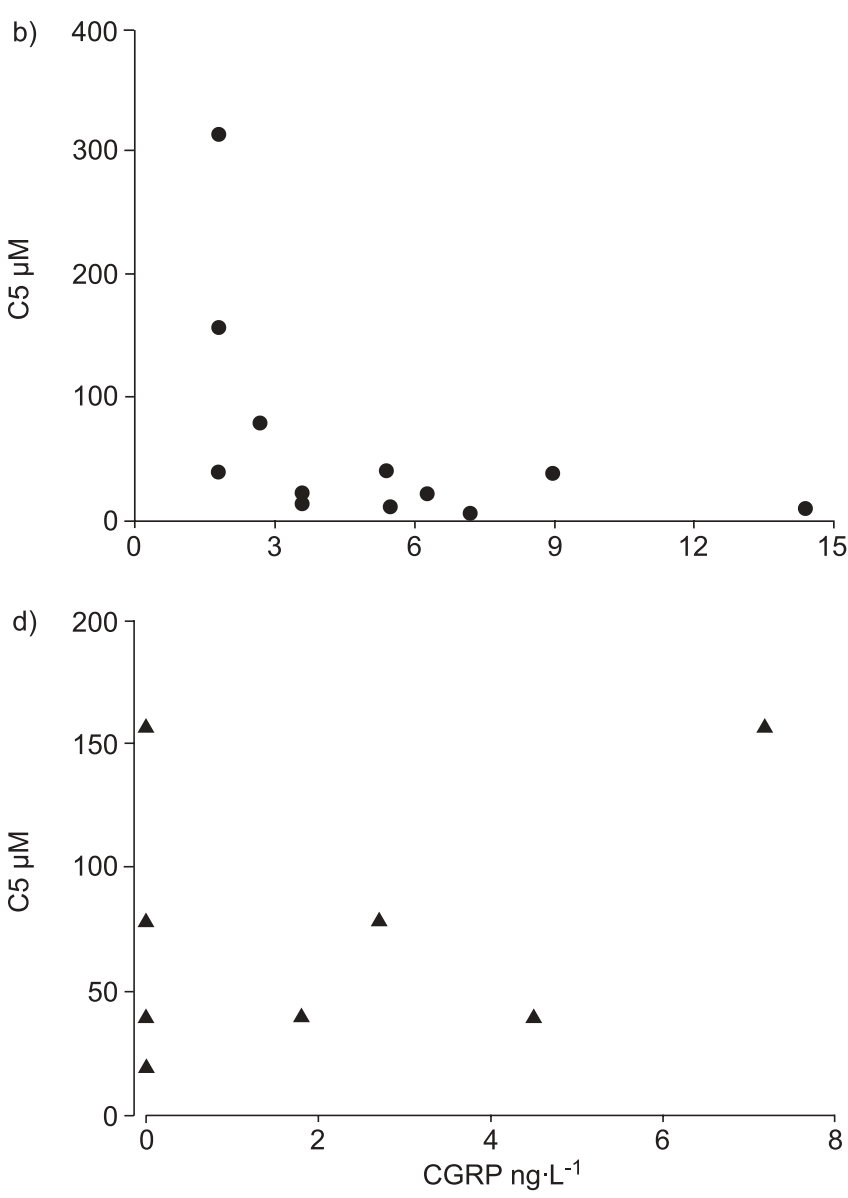

FIGURE 2. Scatter plots of capsaicin concentration that stimulated $\geqslant 2$ coughs (C2; a and c) and capsaicin concentration that stimulated $\geqslant 5$ coughs (C5; b and d) in coughers $(-)$ and noncoughers $(\mathbf{\Lambda})$. C2 and C5 significantly negatively correlated ( $r=-0.51$ and -0.55 , respectively) to calcitonin gene-related peptide (CGRP) in coughers There was no significant correlation between capsaicin cough sensitivity outcomes to CGRP in noncoughers. Note that the total number of data points is $<40$ as data on capsaicin cough sensitivity can only be obtained in older children (aged $>6$ yrs [8]). a) $r=-0.51, p=0.031 ; b) r=-0.55, p=0.020 ; c) r=0.28, p=0.298$; and d) $r=0.29, p=0.324$.

Using the animal model of acid GORD, two groups have demonstrated that oesophageal stimulation by hydrochloric acid causes neurogenic inflammation in the major airways [19, 30]. In support of this, the present authors found that CGRP was significantly different between coughers and noncoughers within the group that also had RO. This suggests that RO is a necessary factor for this difference and that in the absence of RO, CGRP may be less important. The possible reasons for this finding are at least three-fold. First, the same sensory nerves supply the oesophagus and the airways via a long axon route. CANNING [31] argues that gastric "refluxate can directly activate nociceptive nerves in the mucosa of the oesophagus, the pharynx, and the lower airways". Secondly, afferents from the oesophagus in some way link up with and modify (upregulate) afferents from the airways, at either ganglionic or brainstem levels. Upregulation of the peripheral sensory neurones and brainstem regions has been described in animal studies $[32,33]$. A third possibility is that patients with $\mathrm{RO}$ also have aspiration, which in some cases, but not all, causes "chronic" cough. There are arguments for and against each of these possibilities, and further studies are required to evaluate these possibilities.
Ideally, CGRP and cough sensitivity should be re-measured upon the resolution of the cough in the present cohort of children. However, given that a general anaesthetic is necessary to obtain BAL in the present setting, this was not feasible and is thus one of the present study's shortfalls. Also, an association in no way proves "cause and effect" or "which occurred first". Another possible limitation is that although international guidelines for BAL in children were utilised [34], it is unknown if neuropeptides in BAL obtained by nonbronchoscopic methods differ from those obtained using a bronchoscope. Furthermore, although a moderately strong correlation between cough sensitivity and CGRP was found in coughers but not in noncoughers, it was not demonstrated that CGRP was higher in the total cohort of coughers compared with noncoughers. However, this and other nonsignificant findings are possibly related to the small sample size.

Lack of the role of SP or NKA in the present study is consistent with other studies involving cough and the lower airways [17, 18]. In the study by FORSYTHE et al. [17], CGRP but not NKA or $\mathrm{SP}$ induced BAL mast cells to release histamine in chronic coughers. Also, O'CONNELL et al. [18] described increased 
CGRP- but not SP-immunoreactive nerves in airway biopsies of adults with chronic cough.

Neurotrophins and VRs are important concepts in the pathophysiology of chronic cough, as described in biopsy specimens and animal models [13, 35]. However, these markers were not measured in the present study, because in a previous study of 69 children (unpublished data), the present authors also found no difference in brain-derived neurotrophic factor or VR-1 mRNA in BAL cells between children with $(\mathrm{n}=36)$ and without cough $(\mathrm{n}=33)$. Also, CHAUDHURI et al. [36] described that neurotrophins were not elevated in induced sputum or serum of adults with chronic persistent cough.

In a previous study [21], the present authors have also described a small but significantly reduced airway neutrophil percentage in children with $\mathrm{RO}$ without cough. This finding is also similar to a small $(n=11)$ study in adults with GORD and cough [37]. Additionally, the present study's limitations with respect to other diagnostic modalities of GORD has been discussed in previous papers [20,21] and thus is not repeated here. Similarly, the lack of association between cough and GORD in children was also the main discussion point in a previous paper [20]. Cough is rarely solely attributed to RO in otherwise well children [20,38,39], which is in contrast to adults [40]. Cough, symptoms of GORD and asthma are common; an association does not imply cause and effect [41], and the likelihood of these symptoms co-existing merely by chance is high [23].

A larger study, and one that includes follow-up of children with cough and bronchoalveolar lavage, is necessary to confirm the present findings. Nevertheless, the unique findings in the present study were two-fold. First, children with cough and biopsy-proven reflux oesophagitis had significantly higher calcitonin gene-related peptide levels in their bronchoalveolar lavage compared with children with reflux oesophagitis but without cough. This raises the question of plausible mechanisms of cough in reflux oesophagitis and it is likely that other factors are required to be present for reflux oesophagitis to elicit cough in humans. These factors are likely to include persistent neurogenic airway inflammation [12], and the present data support this. Second, calcitonin gene-related peptide, but not substance $\mathrm{P}$ or neurokinin $\mathrm{A}$, related significantly to capsaicin cough sensitivity in children with chronic cough but not to those without cough. It was concluded that elevated calcitonin gene-related peptide, but not substance $\mathrm{P}$ or neurokinin $\mathrm{A}$, is associated with chronic cough in children when oesophagitis coexists. Calcitonin generelated peptide is likely to be an important neuropeptide in chronic cough when reflux oesophagitis coexists. The role of calcitonin gene-related peptide in bronchoalveolar lavage and serum deserves further evaluation.

\section{ACKNOWLEDGEMENTS}

The authors are grateful to M. DaSilva, the doctors and nurses of the Dept of Gastroenterology, Royal Children's Hospital, as well as the anaesthetists, in particular C. Beem, for their assistance in the present study. The authors are grateful to the children and parents who kindly participated in this study.

\section{APPENDIX}

The protease inhibitor cocktail contained the following reagents: 1) soyabean trypsin inhibitor (Sigma Chemical Co., St Louis, MO, USA), $0.002 \mathrm{~g}$ in $200 \mu \mathrm{L}$ PBS; 2) apoprotinin (Sigma Chemical Co.), $0.001 \mathrm{~g}$ in $200 \mu \mathrm{L} 100 \%$ ethanol; 3) $\alpha_{1^{-}}$ antitrypsin (Sigma Chemical Co.), $0.002 \mathrm{~g}$ in $200 \mu \mathrm{L}$ PBS; 4) pepstatin A (Sigma Chemical Co.), $0.002 \mathrm{~g}$ in $200 \mu \mathrm{L}$ PBS; 5) phenanthroline (Sigma Chemical Co.), $0.001 \mathrm{~g}$ in $200 \mu \mathrm{L} \mathrm{100 \%}$ ethanol; 6) ethylenediamine tetraacetic acid (Aldrich Chemicals Ltd, Poole, UK), $0.0005 \mathrm{~g}$ in $200 \mu \mathrm{L}$ PBS; and 7) benzamidine (Sigma Chemical Co.), $0.01 \mathrm{~g}$ in $200 \mu \mathrm{L}$ PBS.

\section{REFERENCES}

1 Irwin RS, French CT, Fletcher KE. Quality of life in coughers. Pulm Pharmacol Ther 2002; 15: 283-286.

2 Fuller P, Picciotto A, Davies M, McKenzie SA. Cough and sleep in inner-city children. Eur Respir J 1998; 12: 426-431.

3 Chang AB, Phelan PD, Robertson CF. Cough receptor sensitivity in children with acute and non-acute asthma. Thorax 1997; 52: 770-774.

4 Chang AB, Phelan PD, Sawyer SM, Del Brocco S, Robertson CF. Cough sensitivity in children with asthma, recurrent cough, and cystic fibrosis. Arch Dis Child 1997; 77: 331-334.

5 O'Connell F, Thomas VE, Pride NB, Fuller RW. Capsaicin cough sensitivity decreases with successful treatment of chronic cough. Am J Respir Crit Care Med 1994; 150: 374-380.

6 Choudry NB, Fuller RW. Sensitivity of the cough reflex in patients with chronic cough. Eur Respir J 1992; 5: 296-300.

7 Torrego A, Haque RA, Nguyen LT, et al. Capsaicin cough sensitivity in bronchiectasis. Thorax 2006; 61: 706-709.

8 Chang AB, Phelan PD, Roberts RGD, Robertson CF. Capsaicin cough receptor sensitivity test in children. Eur Respir J 1996; 9: 2220-2223.

9 Groneberg DA, Quarcoo D, Frossard N, Fischer A. Neurogenic mechanisms in bronchial inflammatory diseases. Allergy 2004; 59: 1139-1152.

10 Belvisi MG. Sensory nerves and airway inflammation: role of A delta and C-fibres. Pulm Pharmacol Ther 2003; 16: 1-7.

11 Widdicombe JG. Sensory neurophysiology of the cough reflex. J Allergy Clin Immunol 1996; 98: S84-S90.

12 Gibson PG. Cough is an airway itch? Am J Respir Crit Care Med 2004; 169: 1-2.

13 Groneberg DA, Niimi A, Dinh QT, et al. Increased expression of transient receptor potential vanilloid-1 in airway nerves of chronic cough. Am J Respir Crit Care Med 2004; 170: 1276-1280.

14 Lee MG, Undem BJ, Brown C, Carr MJ. Effect of nociceptin in acid-evoked cough and airway sensory nerve activation in guinea pigs. Am J Respir Crit Care Med 2006; 173: 271-275.

15 Ichikawa H, Sugimoto T. VR1-immunoreactive primary sensory neurons in the rat trigeminal ganglion. Brain Res 2001; 890: 184-188.

16 Springer J, Geppetti P, Fischer A, Groneberg DA. Calcitonin gene-related peptide as inflammatory mediator. Pulm Pharmacol Ther 2003; 16: 121-130.

17 Forsythe P, McGarvey LP, Heaney LG, MacMahon J, Ennis M. Sensory neuropeptides induce histamine release from bronchoalveolar lavage cells in both nonasthmatic 
coughers and cough variant asthmatics. Clin Exp Allergy 2000; 30: 225-232.

18 O'Connell F, Springall DR, Moradoghli-Haftvani A, et al. Abnormal intraepithelial airway nerves in persistent unexplained cough? Am J Respir Crit Care Med 1995; 152: 2068-2075.

19 Daoui S, Agostino B, Gallelli L, Emonds X, Rossi F, Advenier C. Tachykinins and airway microvascular leakage induced by $\mathrm{HCl}$ intra-oesophageal instillation. Eur Respir J 2002; 20: 268-273.

20 Chang $\mathrm{AB}, \mathrm{Cox} \mathrm{NC}$, Faoagali J, et al. Cough and reflux esophagitis in children: their co-existence and airway cellularity. BMC Pediatr 2006; 6: 4.

21 Chang AB, Cox NC, Purcell J, et al. Airway cellularity, lipid laden macrophages and microbiology of gastric juice and airways in children with reflux oesophagitis. Respir Res 2005; 6: 72.

22 Rudolph CD, Mazur LJ, Liptak GS, et al. Guidelines for evaluation and treatment of gastroesophageal reflux in infants and children: recommendations of the North American Society for Pediatric Gastroenterology and Nutrition. J Pediatr Gastroenterol Nutr 2001; 32: Suppl. 2, S1-S31.

23 Chang $\mathrm{AB}$, Lasserson TJ, Kiljander TO, Connor FL, Gaffney JT, Garske LA. Systematic review and metaanalysis of randomised controlled trials of gastro-oesophageal reflux interventions for chronic cough associated with gastro-oesophageal reflux. BMJ 2006; 332: 11-17.

24 Chang $A B$, Newman RG, Carlin JB, Phelan PD, Robertson CF. Subjective scoring of cough in children: parent-completed vs child-completed diary cards vs an objective method. Eur Respir J 1998; 11: 462-466.

25 Hibbert ME, Lannigan A, Landau LI, Phelan PD. Lung function values from a longitudinal study of healthy children and adolescents. Pediatr Pulmonol 1989; 7: 101-109.

26 Warke TJ, Kamath S, Fitch PS, Brown V, Shields MD, Ennis M. The repeatability of nonbronchoscopic bronchoalveolar lavage differential cell counts. Eur Respir J 2001; 18: 1009-1012.

27 Barnes PJ. Neurogenic inflammation in the airways. Respir Physiol 2001; 125: 145-154.

28 Canning BJ, Mazzone SB, Meeker SN, Mori N, Reynolds SM, Undem BJ. Identification of the tracheal and laryngeal afferent neurones mediating cough in anaesthetized guinea-pigs. J Physiol 2004; 557: 543-558.

29 Hsu JH, Yeh JL, Dai ZK, Chen IJ, Wu JR. Increased circulating calcitonin gene-related peptide in congestive heart failure caused by congenital heart disease. Int Heart J 2005; 46: 867-875.

30 Kohrogi H, Hamamoto J, Kawano O, et al. The role of substance $\mathrm{P}$ release in the lung with esophageal acid. Am J Med 2001; 111: Suppl. 8A, 25S-30S.

31 Canning BJ. Role of nerves in asthmatic inflammation and potential influence of gastroesophageal reflux disease. Am J Med 2001; 111: 13-17.

32 Joad JP, Sekizawa S, Chen CY, Bonham AC. Air pollutants and cough. Pulm Pharmacol Ther 2007; 20: 347-354.

33 Bonham AC, Sekizawa S, Chen CY, Joad JP. Plasticity of brainstem mechanisms of cough. Respir Physiol Neurobiol 2006; 152: 312-319.

34 de Blic J, Midulla F, Barbato A, et al. Bronchoalveolar lavage in children. ERS Task Force on bronchoalveolar lavage in children. European Respiratory Society. Eur Respir J 2000; 15: 217-231.

35 Canning BJ. Anatomy and neurophysiology of the cough reflex: ACCP Evidence-Based Clinical Practice Guidelines. Chest 2006; 129: Suppl. 1, 33S-47S.

36 Chaudhuri R, McMahon AD, McSharry CP, et al. Serum and sputum neurotrophin levels in chronic persistent cough. Clin Exp Allergy 2005; 35: 949-953.

37 Parameswaran K, Allen CJ, Kamada D, Efthimiadis A, Anvari M, Hargreave FE. Sputum cell counts and exhaled nitric oxide in patients with gastroesophageal reflux, and cough or asthma. Can Respir J 2001; 8: 239-244.

38 Shields MD. Diagnosing chronic cough in children. Thorax 2006; 61: 647-648.

39 Marchant JM, Masters IB, Taylor SM, Cox NC, Seymour GJ Chang AB. Evaluation and outcome of young children with chronic cough. Chest 2006; 129: 1132-1141.

40 McGarvey LP, Heaney LG, Lawson JT, et al. Evaluation and outcome of patients with chronic non-productive cough using a comprehensive diagnostic protocol. Thorax 1998; 53: 738-743.

41 Field SK, Sutherland LR. Gastroesophageal reflux and asthma: are they related? J Asthma 1999; 36: 631-644. 